\title{
Research on the Influence of Heterogeneous Beliefs and Media Reports on Investor Behavior from the Perspective of Informationization
}

\author{
Fengyun Liang ${ }^{1, *}$ \\ School of economics and management, Lan Zhou University of Technology, Lan Zhou, China
}

\begin{abstract}
Based on the background of informatization, the development and progress of science and technology has brought an immeasurable impact on the securities market. Therefore, this article uses python technology to crawl the number of individual stock news and study the influence of media attention on investor behavior under the constraint of heterogeneous beliefs. It is found that there is a significant positive correlation between the degree of media attention and the degree of investors' heterogeneous beliefs, and investors are more likely to choose stocks that are frequently reported by the media; further research has found that media reports intensify the degree of investor's heterogeneous beliefs, leading to stock transactions .The amount has risen abnormally. Therefore, while enjoying informatization, it is necessary to guard against the risks it bring.
\end{abstract}

\section{Introduction}

The innovation of information technology and financial products has brought major changes to the trading mechanism and trading structure of the securities market. On the one hand, the impact of information technology on the trading system of the securities market has improved the efficiency of market transactions; on the other hand, it has also contributed to the health of the stock market. Development has brought challenges. Informatization has brought about social networking platforms, which have greatly affected investors' decision-making behaviors and aroused in-depth research by scholars. Although Internet media, as the most important information platform at the moment, is capable of disseminating information in a timely and extensive manner, the majority of individual investors in the domestic market have deviations in their cognitive abilities and professional knowledge. Therefore, the era of big data may cause investors to face the increasingly complex information environment has triggered their irrational investment behaviors, brought many unknown risks to the financial market, affected the stable development of the stock market, and laid huge hidden dangers for future investment.

Since the advent of behavioral finance, research on investor behavior has been "sought after" by many scholars. The main research focuses on irrational behavior and stock returns, herding effect, etc. In the information age, many scholars have also found that online media reports will have an impact on investor behavior. At present, there are two main aspects to the investigation of investor behavior in online media reports at home and abroad. One is the research on the mechanism of media reports affecting investor behavior. The second is to study the impact of media reports on investor behavior. Foreign scholars Chen and Yang (2007) ${ }^{[1]}$ found that the dynamic interaction between information diffusion and belief changes creates continuity and reversal; Leon and Arafia $(2016)^{[2]}$ believe that many human behaviors are not made under the condition of complete cognition, but are formed under the driving force similar to animal spirits. Domestic scholar Rao Yulei et al. (2010) ${ }^{[3]}$ discovered the "media effect"; Li Jinliang et al. (2018) ${ }^{[4]}$ used the data in "Baidu Stock Market" to study the impact of online public opinion and investor attention on stock prices, and found that stocks that are highly sought after by the media have excess returns in the short term and reverse the next day. Is the serious heterogeneous belief of individual investors in my country's stock market the real "pathogen" that causes the frequent occurrence of stock return anomalies, and will the rapid development of Internet media cause greater deviations in investor beliefs? Only by solving these problems can we have a deep understanding of the development status of my country's securities market, can effectively play the role of resource allocation in my country's securities market, and ensure the stable development of the stock market. Only by thoroughly understanding the role of informatization in the securities market, especially in the immature financial market of our country, can we achieve the maximum effectiveness of informatization in a targeted manner, and in-depth discussion of the influence of online media platforms on investor behavior, in order to better promote the more long-term and stable development of my country's securities market.

*Corresponding author: 2824297360@qq.com 


\section{Theoretical analysis and research hypothesis}

\subsection{The impact of media reports on investors' heterogeneous beliefs}

The development of information technology has spawned a series of online social platforms, which publish countless information related to stock prices every day, and there is vicious competition, which in turn induces investors to make irrational investment decisions. Moreover, the first thing that is affected is the beliefs of investors. The initial beliefs of each investor are not the same. Due to the influence of this unproven information, their beliefs have changed. Traditional financial theory believes that investors are completely rational and homogeneous, and stock prices can reflect any information they need, so information from the company level or media reports on stocks will not affect investors' behavior, nor will investors obtain excess returns, but the reality is not like this. Why is this? The discipline of economic psychology believes that the factors that affect investor behavior are not only related to market information, but also closely related to their psychological characteristics. Investors' complex psychological changes such as heterogeneous beliefs and other factors always affect investors' decision-making behavior. Kim J, Leung T. (2016) ${ }^{[5]}$ found that the key to triggering a transaction is mainly the heterogeneity of investor beliefs, not the difference in risk aversion. Behavioral economists Terence Odin and Brad Barber believe that the stock market environment facing investors will get worse and worse, because the massive amount of information on the Internet will allow investors to easily anchor information that supports their predictions, prompting investors to form excessive self-confidence, not being cautious, leading to irrational behavior. When social media is consistent with their expectations, it will promote their heterogeneous belief levels, and then make wrong decisions, not only harm their own interests, but also hinder the normal operation of the market. Therefore, the first hypothesis of this article is proposed:

H1: There is a positive correlation between investor heterogeneous beliefs and media attention.

\subsection{The impact of media attention on investor behavior from the perspective of heterogeneous beliefs}

In the unpredictable securities market, stock prices respond very quickly to information. If investors can grasp the latest information for the first time, they are likely to make a profit. Therefore, they pay much attention to the speed and quantity of information released. However, most individual investors are short-sighted, with improper investment motives, focusing only on immediate benefits, but ignoring the risks behind them, thus blindly following the trend of media reports. In the unpredictable securities market, stock prices respond very quickly to information. Some scholars found that public disclosure of information would aggravate investor heterogeneous belief differences; some scholars have found that the Internet media' $\mathrm{s}$ disclosure and dissemination of listed company information will directly affect the company' $s$ image in the minds of investors, and will produce heterogeneous beliefs in the use of public opinion to guide investors and influence investors decision-making process. Sometimes the media, in order to pursue the effect of public opinion and gain the public' $\mathrm{s}$ attention, will report hype hot events and issues. At the same time, it will provide readers with entertainment-oriented or interesting reports in order to compete and make huge profits. Moreover, limited rational investors will also interpret the same information. There will be differences, and different judgments on the information reported by the media will cause differences, which will affect their judgments on the expected return distribution of stocks, that is, deepen their degree of heterogeneous beliefs. Tang Yong et al. (2020) ${ }^{[4]}$ believed that investors' psychological activities would be affected by the amount of media and emotional tendencies, and follow suit the behavior caused market turbulence. The initial beliefs of investors are not consistent. When faced with the massive amount of information in the market, they usually do not realize that they are at an information disadvantage or are too optimistic about their own decisions, so they rarely pay attention to the trading information of other participants in the market. Moreover, limited rational investors will have different interpretations of the same information, and different judgments of the information reported by the media will cause differences, which affects their judgments on the expected return distribution of stocks. Individual investors believe too much in their ability to interpret information while ignoring their own psychological changes and the influence of the surrounding environment, which leads to an increase in the degree of heterogeneous beliefs. Moreover, investors with limited rationality will have different interpretations of the same information. The different judgments of the media reported on the information produced differences, which affected their judgments on the expected return distribution of stocks, that is, deepened their degree of heterogeneous beliefs. The second hypothesis of this article:

H2: Media reports will aggravate investors' heterogeneous beliefs, deepen their irrational investment behaviors, and cause an increase in stock trading volume.

\section{Research design and empirical test}

\subsection{Data source and sample analysis}

This article uses two methods to crawl the daily news items of individual stocks on the Oriental Fortune website: one is to search for abbreviations; the other is to 
search for codes. Select listed companies listed in Lushi, in order to ensure that online news contains more fundamental information of listed companies, obtain transaction data for the period from April 1, 2019 to March 31, 2020 in the Guotaian database (CSMAR), a total of 38 listed companies. The main variables in this article are: trend turnover rate (Beliefsturn), media attention (Med), abnormal trading volume (AV), comparable price (Comprice), company size (Sca).

\subsection{Empirical test}

\subsubsection{Correlation analysis of main variables}

Table 1 is the correlation statistical analysis.

Table 1 Correlation analysis results of main variables

\begin{tabular}{|c|c|c|c|c|c|}
\hline & AV & Beliefsturn & Comprice & Med & Sca \\
\hline AV & 1 & & & & \\
\hline Beliefsturn & $0.746 \star \star \star$ & 1 & & & \\
\hline Comprice & $-0.151 \star \star \star$ & $-0.096 \star \star \star$ & 1 & & \\
\hline Med & $0.170 \star \star \star$ & $0.193 \star \star \star$ & $0.257 \star \star \star$ & 1 & \\
\hline Sca & $-0.176 \star \star \star$ & $-0.104 \star \star \star$ & $0.786 \star \star \star$ & $0.249 \star \star \star$ & 1 \\
\hline
\end{tabular}

As shown in Table 2, the coefficient of media attention and investor heterogeneous beliefs is 0.193 , indicating that there is a significant positive relationship between the two; media attention, investor heterogeneous beliefs and transaction volume have a significant positive correlation. The coefficients are 0.170 and 0.746 , respectively, indicating that investors;' heterogeneous beliefs and media reports will have a positive impact on stock trading volume.

\subsubsection{Empirical test and result analysis}

Table 2 Regression results of media attention and investor heterogeneous trust

\begin{tabular}{c|cccccc} 
Med & Coef. & Std. & $\mathrm{t}$ & $\mathrm{P}>|\mathrm{t}|$ & {$[95 \%$ Conf. Interval $]$} \\
\hline Belifsturn & $.02770^{* * *}$ & .0012 & 22.85 & 0.000 & .0253 & .0301 \\
Sca & $.04768^{* * *}$ & .0054 & 8.80 & 0.000 & .0371 & .0583 \\
Comprice & $.05713^{* * *}$ & .0053 & 10.70 & 0.000 & .0467 & .0676 \\
_cons & $-1.0675^{* * *}$ & .1090 & -9.79 & 0.000 & -1.2812 & -.8537 \\
R-squared & & \multicolumn{5}{c}{0.121} \\
F & & 425.62 & \\
Obs & & 9,257
\end{tabular}

For Hypothesis 2, in order to verify the influence of investors' heterogeneous beliefs on the above content, in order to fully understand the influence of media attention on investors' behavior under heterogeneous beliefs,

$$
A V_{i, t}=\alpha_{i, 0}+\beta \text { Beliefsturn }_{i, t}+\text { OMed }_{i, t}+\eta \text { Beliefsturn }_{i, t} \times \text { Med }_{i, t}+\sum \gamma \text { Control }_{i, t}+\varepsilon_{i, 0}
$$

The statistical results of Stata are shown in Table 3. The trend turnover rate, media attention and the interaction coefficients of the two are all positive, which are $0.4659,0.13399$, and 0.1078 , respectively, and are significant at the 0.01 significance level. It shows that the degree of media attention will directly affect investor

behavior, and when investors' heterogeneous beliefs are more divergent, media reports will have a stronger impact on investor behavior, which will cause irrational behavior of investors and increase transaction volume. Assumption 2 is proved.

Table 3 Results of the influence of media attention on investor behavior under heterogeneous beliefs

\begin{tabular}{c|cccccc}
\multicolumn{1}{c}{ AV } & Coef. & Std. Err. & $\mathrm{t}$ & $\mathrm{P}>|\mathrm{t}|$ & \multicolumn{2}{c}{$[95 \%$ Conf. Interval] } \\
\hline \multirow{2}{*}{$\begin{array}{c}\text { Belifsturn } \\
\text { Med }\end{array}$} & $.4659^{* * *}$ & .0065 & 71.62 & 0.000 & .4531 & .4786 \\
& $.1340^{* * *}$ & .0450 & 2.98 & 0.003 & .0458 & .2221 \\
\hline
\end{tabular}




\begin{tabular}{c|cccccc} 
Belifsturn*Med & $.10780^{* * *}$ & .0077 & 13.98 & 0.000 & .0927 & .1229 \\
Sca & $-.1935^{* * *}$ & .0221 & -8.75 & 0.000 & -.2369 & -.1502 \\
Comprice & -.0242 & .0218 & -1.11 & 0.268 & -.0669 & .0186 \\
cons & $6.2232^{* * *}$ & .4458 & 13.96 & 0.000 & 5.3494 & 7.0970 \\
R-squared & & \multicolumn{7}{c}{0.5779} \\
F & & & \\
Obs & & $9,2535.62$ & \\
\end{tabular}

\section{Research conclusions and countermeasures}

Based on the current information age, this article attempts to study the influence of Internet media on investor behavior from the perspective of heterogeneous beliefs, combined with the peculiarities of my country's financial market, and first study the relationship between media attention and investor beliefs. Then, on this basis, we explore the influence of media reports on the behavior of investors with heterogeneous beliefs. This paper uses the data of $38 \mathrm{~A}$-share listed companies, and through theoretical analysis and empirical testing, the following conclusions are obtained: 1. Media reports on listed companies are significantly positively correlated with investors' heterogeneous beliefs, and investors are more inclined to pay attention to the media the stocks with higher attention; 2. It is that the news media will strengthen the heterogeneous belief level of investors to a certain extent, will strengthen the belief divergence of market participants, lead to their irrational behavior, and cause the increase in stock trading volume.

This article finds that investor psychology is easily dominated by the news media, and media reports will also deepen the fluctuations in the stock market caused by changes in investors' heterogeneous beliefs, and ultimately lead to irrational behaviors of investors, resulting in large fluctuations in trading volume and disrupting market order. According to the above conclusions, the following enlightenment can be obtained: According to the above conclusions, the following enlightenment can be obtained: Internet media should be responsible for their own remarks, should maintain a neutral attitude, have a certain sense of social responsibility, and timely disclose the true internal situation of the company to provide various types of investors, especially individual investors. Effective value helps them make more reasonable decisions. The most important point is that the Internet media must have a clear stand, firmly refuse to cooperate with listed companies to deceive the public, strengthen the supervision of the authenticity and controllability of the information released by the Internet media, and further improve the media information disclosure of my country's stock market. Relevant laws and regulations, to ensure that there are laws to follow in the market, and that there are laws to be enforced, to ensure that investors can fully understand the operating conditions of listed companies in a timely manner and provide timely feedback on the stock price; at the same time, it is necessary to strengthen the education of investors and keep holding There are risks in entering the market, and investment must be cautious, analyze network information objectively, and invest rationally. For investors themselves, they must not only learn financial market knowledge, broaden their horizons, enrich their experience, improve their investment concepts and risk prevention awareness, improve their psychological quality of resisting market risks, but also improve their own ability to discern the authenticity of information. Ability to face market information rationally, minimize differences in beliefs, reduce irrational investment behavior, and ensure the healthy, efficient and stable development of the securities market.

\section{References}

1. Chen Z, Yang X . Heterogeneous Beliefs, Trading Volume, and Seemingly Emotional Stock Market Behavior[J].Tsinghua Science and Technology, 2007, 12(3).

2. ]Leon C J , Arana J E . The Economic Valuation of Climate Change Policies in Tourism Impact of Joint Valuation, Emotions, and Information [J]. Journal of Travel Research, 2016, 55(3).

3. Rao Yulei, Peng Diefeng, Cheng Dachao. Will media attention cause abnormal stock returns? - Empirical evidence from the Chinese stock market[J]. Systems Engineering Theory and Practice, 2010, 30(2).

4. Li Jinliang, He Chengying, Liao Dan, He Muyuan. The influence of public opinion, limited attention and overreaction[J]. Economic Research, 2018, (03).

5. Kim J , Leung T . Impact of risk aversion and belief heterogeneity on trading of defaultable claims[J]. Annals of Operations Research, 2016, 243(1-2).

6. Tang Yong, Hong Xiaomei, Zhu Pengfei. Limited attention and abnormal characteristics of stock market, herd effect[J]. Financial Theory and Practice, 2020(1). 